\title{
ASO Visual Abstract: Albumin-Derived NLR Score is a Novel Prognostic Marker for Esophageal Squamous Cell Carcinoma
}

\section{Tomoki Abe, MD¹, Taro Oshikiri, MD¹, Hironobu Goto, MD $^{1}$, Takashi Kato, MD $^{1}$,} Manabu Horikawa, MD ${ }^{1}$, Ryuichiro Sawada, MD ${ }^{1}$, Hitoshi Harada, MD ${ }^{1}$, Naoki Urakawa, MD ${ }^{1}$, Hiroshi Hasegawa, $\mathrm{MD}^{1}$, Shingo Kanaji, $\mathrm{MD}$, $\mathrm{PhD}^{1}$, Kimihiro Yamashita, MD, $\mathrm{PhD}^{1}$, Takeru Matsuda, $\mathrm{MD} \mathrm{PhD}^{2}$, and Yoshihiro Kakeji, $\mathrm{MD}, \mathbf{P h D}^{1}$

${ }^{1}$ Division of Gastrointestinal Surgery, Department of Surgery, Graduate School of Medicine, Kobe University, Kobe, Hyogo, Japan; ${ }^{2}$ Division of Minimally Invasive Surgery, Department of Surgery, Graduate School of Medicine, Kobe University, Kobe, Hyogo, Japan

Nutritional and inflammatory indicators were reported to be associated with cancer prognosis. The combination of albumin and the derived neutrophil-to-lymphocyte ratio (Alb-dNLR) score is one of these indicators. We showed that the Alb-dNLR score was an independent prognostic predictor for overall survival and cause-specific survival in thoracic esophageal squamous cell carcinoma patients treated with esophagectomy (https://doi.org/10.1245/s104 34-021-11012-y).

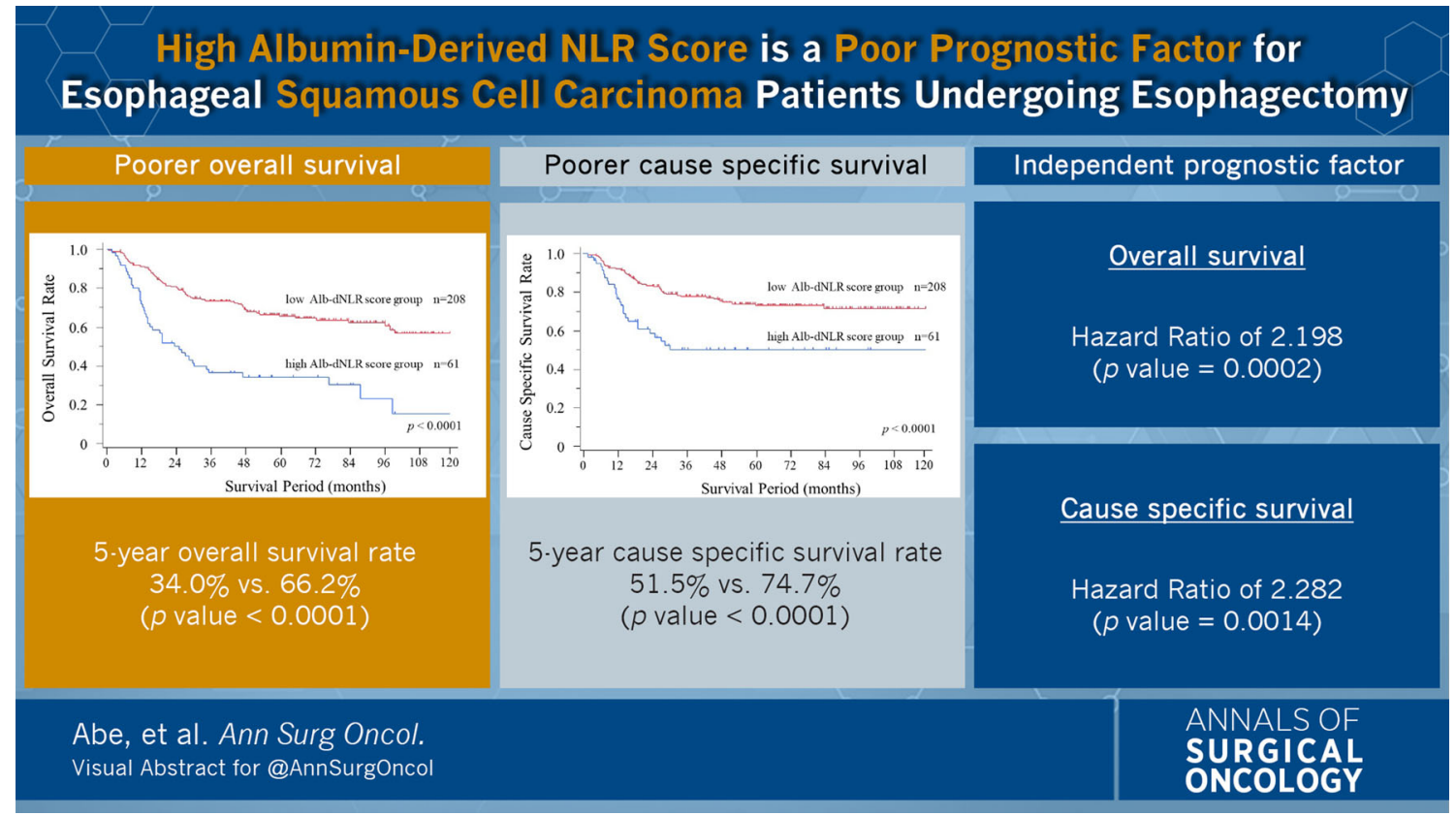

DISCLOSURES The authors have no conflicts of interest or financial ties to disclose.

(C) Society of Surgical Oncology 2021

T. Oshikiri, MD

e-mail: oshikiri@med.kobe-u.ac.jp
Publisher's Note Springer Nature remains neutral with regard to jurisdictional claims in published maps and institutional affiliations. 